\title{
Severe Deep Neck Space Infection and Bilateral Pneumonia of Odontogenic Origin: a Case Report
}

Ilze Dobele*, Gints Kragis**, Girts Salms***, Peteris Apse**

*Department of Otolaryngology, Riga Stradinš University, Latvia

**Department of Prosthetic Dentistry, Riga Stradinš University, Latvia

***Department of Oral and Maxillofacial Surgery, Riga Stradinsš University, Latvia

\section{Summary}

Severe deep neck infections (DNIs) are potential complications of odontogenic pathology. DNIs affecting perimandibular space have a high prevalence and their etiologic and therapeutic aspects have been discussed. Early diagnosis and aggressive antimicrobial and surgical treatment are essential to successfully treat cervical abscesses and compromised upper airways of odontogenic origin. We report the case of life threatening pathology involving perimandibular, retropharyngeal spaces and bilateral pneumonia.

Key words: dental focal infection, abscess, difficult airway, deep neck infection, pneumonia.

\section{AIM OF THE DEMONSTRATION}

The aim of the article is to demonstrate a severe lifethreatening pathology of dental origin and necessity of interdisciplinary collaboration for early diagnosis and appropriate management.

\section{CASE REPORT}

29 years old male was seeking for urgent help in the regional hospital regarding complaints about increasing breathing and swallowing difficulties and submandibular swelling lasting for 3 days. No dental pain was present. Dental and deep neck infection as well as laryngeal stenosis was diagnosed and patient urgently transported to the intensive care unit of the P. Stradiņš Clinical University hospital.

Clinical data: severe general status, conscious, hoarseness, stridorous breathing 28 times per minute, tachicardia 116 times per minute, forced posture sitting, febrility $39,2^{\circ} \mathrm{C}$, localised infiltration, redness and palpatory tenderness in the submandibular region. Oral status: restricted movements of tongue, tenderness and pain on percussion $\mathrm{dd} 22,47,48,38$. Laboratory data: white blood cell count 21.6 cells $/ \mathrm{mm}^{3}, \mathrm{C}$-reactive protein $319.4 \mathrm{mg} / \mathrm{l}$, K $4.5 \mathrm{mmol} / \mathrm{l}$.

Radiological investigations:

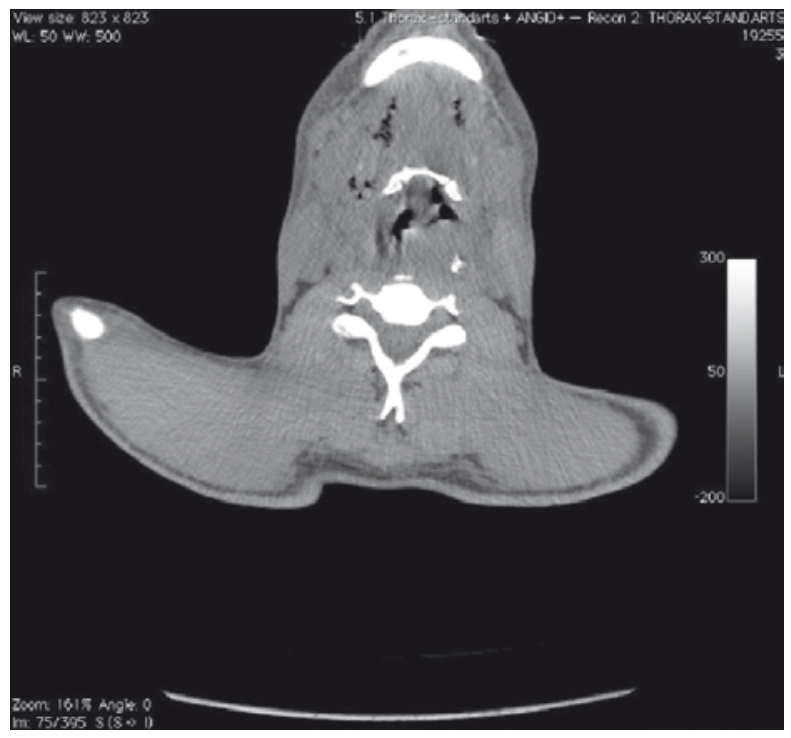

Fig. 1. Axial CT scan of the neck showing a bilateral perimandibular abscesses with compromised larynx 


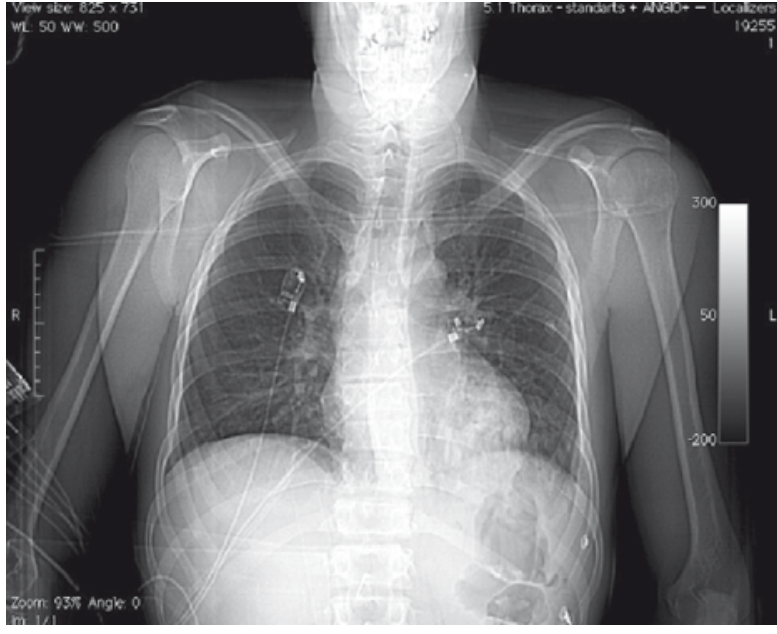

Fig. 2. CT of the chest showing alveolar infiltration in the lower left and middle right segment

Diagnosis: periapical abscesses of dd 22, 38, 47, 48, deep neck infection with laryngeal stenosis and bilateral pneumonia. Antibiotic therapy was begun empirically with Dalacin $600 \mathrm{mg}$ IV $8 \mathrm{~h}$ and Metronidazole 100 mg IV $8 \mathrm{~h}$. E/o (extraoral) incisions and drainage of the submandibular, retropharyngeal abscesses was performed. Tracheostomy done. dd 38, 48, 47 was extracted. Patient was sedated and ventilated (Fig. 3).

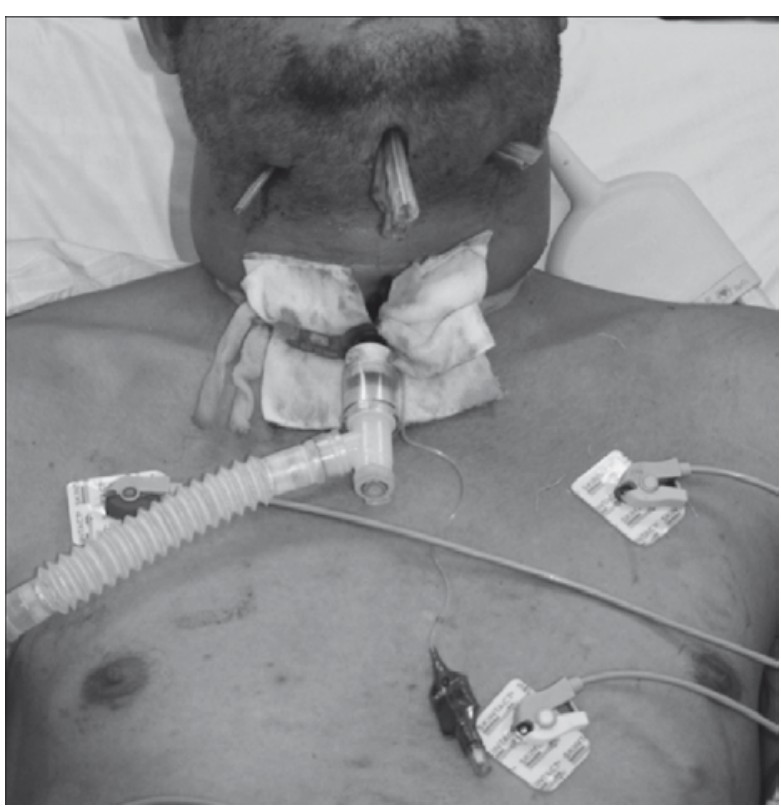

Fig. 3. Extraoral incisions for drainage of submandibular and retropharyngeal spaces. Tracheostomy tube

Next day patient breathes spontaneously through tracheostoma, eating soft food, temperature $36,3^{\circ} \mathrm{C}$, WBC 12.8 cells $/ \mathrm{mm}^{3}$, CRP $115.2 \mathrm{mg} / \mathrm{l}$. Continuous antimicrobial therapy, wound dressing and drainage. 3rd day purulent discharges from drains observed and submandibular infiltration descending to the sternum, painful swallowing. Repeated surgical intervention done, i/v antimicrobial therapy Tazocine 4,5 mg IV $8 \mathrm{~h}$ added. $4-5$ th day infiltration of the neck decreasing , tracheostoma evacuated, patient breath spontaneously, light swallowing and speech difficulties. From intensive care unit transferred to the maxillofacial department for further treatment, p/o antimicrobial therapy continues no less than 3 weeks.

\section{DISCUSSION}

Odontogenic soft tissue infections may spred along the facial planes downwards and cause DNIs, which typically originate from the molar teeth of the mandible $(3,4,6)$. There are two main factors that promote spreading of DNIs towards mediastinum: the cervical anatomy with an almost enclosed space along the facial planes of the neck and chest, and the effects of

gravity and reccurrent changes in the negative intrathoracic pressures that occur with inspiration (1). The reason for the high mortality of deep neck processes descending to the mediastinum is the difficulty in making the early clinical diagnosis (2). The typical signs of descending inflammation with thoracal involvement are reporeted to be pyrexia, dysphagia, swelling and induration of the neck and upper part of the chest, thoracic pain, dyspnea, hypoxia, and respiratory failure (10). However these symptoms are not always evident and often occurs late in the course of disease, therefore radiological assesment is the main non invasive diagnostic tool $(3,5)$. Post surgical follow-up CT examinations help to determine the adequacy of treatment and may indicate surgical revision. Besides sufficient surgical therapy, the adequate choice of antibiotics is of particular importance in the management of DNIs. DNIs most often frequently are polymicrobial processes with Streptococcus and Staphylococcus species as well as anaerobes playing the major pathogenic role (14). Most authors recommend an antibiotic therapy that primarily covers gram-positive, anaerobic as well as beta-lactamase producing bacteria. Commonly recommended choices for empiric antimicrobial therapy are penicillin alone or in combination with metronidazole and clindamicine $(7,14)$.

The surgical procedure of choice is determined by the goal of assure effective abscess drainage to prevent systemic toxicity and subsequent multiorgan failure $(9,12)$.

The prevalence of DNI is high in young and middle-aged adults with a preponderance of males aged 25-33 years. Reduced immune defence, high microbial virulence and smoking habits are predisposing factors (7). Complex head and neck anatomy often makes early DNIs challenging and suspicion is necessary to avoid delay in the treatment. Aggressive management and monitoring of the airways is the most urgent aspect of care as well as surgical drainage and appropriate antibiotic coverage (1, $3,5,9,12)$. Interdisciplinary collaboration is essential for early diagnosis and appropriate management of severe pathologies of odontogenic origin $(8,11,13)$. 


\section{Conflict of interest: None}

\section{REFERENCES}

1. Fragiskos F.D. Odontogenic Infections // In: Fragiskos D. Fragiskos (Ed.) Oral Surgery. Berlin: Springer-Verlag; 2007: 205 - 241

2. Green A.W., Flower E.A., New N.E. Mortality associated with odontogenic infection! // Br Dent J 2001; 190: $529-530$

3. Infections // In: Perry M. (ed). Head, Neck and Dental Emergencies, lst ed. Oxford University Press; 2005: 62 - 75

4. Jacobson J.J., Silverman S. Bacterial Infections // In: Silverman S.S., Eversole L.R., Truelove E.L. Essentials of Oral Medicine. Hamilton, London: BC Decker Inc.; 2001: 159 - 169

5. Lee J.W., Immerman S.B., Morris L.G.T. Techniques for early diagnosis and management of cervicofacial necrotising fasciitis // J of Laryngol \& Otology 2010; 124: $759-764$

6. Li X., Kolltveit K., Tronstad L. et al. Systemic Diseases Caused by Oral Infection // Clin Microbiol Rev, 2000, 10:547 - 558

7. Meurman J.H., Lindqvist C. Livshotande odontogena infektioner. Tema Antibiotika // Tandläkartidningen 2002; 94(1): $18-22$

8. Migliorati C.A., Madrid C. The inteface between oral and systemic health: the need for more collaboration // Clin Microbiol Infect 2007; 13(4): $11-6$
9. Myers E.M. Pharynx and Larynx // In: Britt L.D (ed) Acute Care Surgery: Principles and Practice. Springer Science+Business Media LLC; 2007; $277-304$

10. Paju S., Scannapieco F.A. Oral biofilms, periodontitis, and pulmonary infections // Oral Dis 2007; 13(6):508 - 512

11. Rautemaa R., Lauhio A., Cullinan N.P. et al. Oral infections and systemic disease - an emerging problem in medicine // Clin Microbiol Infect 2007; 13(11): $1041-7$

12. Submandibular - Submental Region (Robbins Level I) // In: Lucioni M. Practical Guide to Neck Dissection. Berlin: Springer-Verlag; 2007; $31-40$

13. Vieira C.L., Caramelli B. The history of dentistry and medicine relationship: could the mouth finally return to the body? // Oral Dis 2009; 15(8):538-46

14. Vieira F., Allen S.M., Stocks R.M.S., Thompson J.W. Deep Neck Infection // Otolaryngol Clin N Am 2008; 41:459-483

\section{Address:}

Ilze Dobele

Department of Otolaryngology, Riga Stradins University

20 Dzirciema Street, LV-1007 Riga Latvia

E-mail: Ilze.Dobele@rsu.lv 